\title{
Copeptin is associated with mortality and outcome in patients with acute intracerebral hemorrhage
}

\author{
Christian Zweifel ${ }^{+1}$, Mira Katann ${ }^{+2,3}$, Philipp Schuetz 3 , Martin Siegemund ${ }^{4}$, Nils G Morgenthaler ${ }^{5}$, Adrian Merlo1, \\ Beat Mueller 3,6 and Mirjam Christ-Crain*3
}

\begin{abstract}
Background: Spontaneous intracerebral hemorrhage $(\mathrm{ICH})$ accounts for a high mortality and morbidity. Early prediction of outcome is crucial for optimized care and treatment decision. Copeptin, the C-terminal part of provasopressin, has emerged as a new prognostic marker in a variety of diseases, but its prognostic value in ICH is unknown.

Methods: In 40 consecutive patients who were admitted to the hospital within 72 hours after a spontaneous ICH, the plasma copeptin level was measured with a sandwich immunoassay upon admission. The prognostic value of copeptin to predict 30 day mortality and functional outcome after 90 days was assessed. A favorable outcome was defined as a Barthel score above 85 and a score below 3 on the Modified Rankin Scale.

Results: Copeptin correlated positively with hematoma volume $(r=0.32, p<0.05)$ and negatively with the Glasgow Coma Scale (GCS) on admission ( $r=-0.35, p<0.05)$. Copeptin levels were higher in patients who died within 30 days than in 30-day survivors (179.0 pmol/I (IQR 33.7- 566.0) vs. $12.9 \mathrm{pmol} / \mathrm{I}(\mathrm{IQR} 5.2-42.8), \mathrm{p}=0.003)$. Copeptin levels were also higher in patients with an unfavorable functional outcome at 90 days compared to patients with a favorable outcome (32.4 pmol/I (IQR 9.5-97.8) vs. 11.9 pmol/I (IQR 3.2-19.8), $p=0.04)$. For the prediction of death, receiveroperating-characteristics analysis revealed an area under the curve (AUC) for copeptin of 0.88 ( $95 \% \mathrm{Cl} 0.75-1.00)$. The predictive value of the copeptin concentration was thus similar to that of GCS (AUC $0.82(95 \% \mathrm{Cl} 0.59-1.00) p=0.53$ ), of the ICH Score (AUC 0.89, (95\%Cl 0.76-1.00), $p=0.94$ ) and the ICH Grading Scale (AUC $0.86(95 \% \mathrm{Cl} 0.69-1.00), p=0.81$ ).

Conclusions: Copeptin is a new prognostic marker in patients with an $\mathrm{ICH}$. If this finding can be confirmed in larger studies, copeptin might be an additional valuable tool for risk stratification and decision-making in the acute phase of $\mathrm{ICH}$.

Trial Registration: (Clinical Trial Registration: ISCTRN00390962)
\end{abstract}

\section{Background}

Intracerebral hemorrhage ( $\mathrm{ICH})$ is more fatal and disabling than ischemic stroke and ranges from 10 to 20 cases per 100,000 population reflecting 10 to 15 percent of all stroke patients [1]. Early prognostication of the risk of death or of a poor long-term outcome would enable optimized care and improved allocation of health-care resources. Several scales of outcome prediction after primary ICH have been proposed [2]. Dynamic factors like hematoma volume expansion, edema formation or per-

* Correspondence: Mirjam.Christ-Crain@unibas.ch

3 Department of Endocrinology and Clinical Nutrition, University Hospital of

Basel, Petersgraben 4, 4031 Basel, Switzerland

+ Contributed equally

Full list of author information is available at the end of the article sistent high blood pressure are known to be associated with early neurologic deterioration and poor outcome[3]. In combination with the clinical findings, a readily measurable predictive marker predicting mortality in patients with ICH would be helpful for early prognostication and risk stratification. Biomarkers are attracting increasing attention as potential predictors of outcome in ischemic and hemorrhagic stroke $[4,5]$.

Copeptin, the C-terminal portion of provasopressin, is a 39-amino acid glycopeptide that has been found to be a stable and sensitive surrogate marker for vasopressin (AVP) release [6]. As AVP is a potent synergistic factor of the hypothalamo-pituitary-adrenal axis, copeptin might act as a marker of the individual stress response. In fact, it 
has been shown that copeptin measurement is useful for prognostic assessment in patients with cardiovascular diseases, lower respiratory tract infection, sepsis and head injury $[7,8]$. Copeptin levels have also been found to be elevated in ischemic stroke patients; in this group of patients, high copeptin levels were highly predictive for poor functional outcome and mortality [9].

We tested the hypothesis that high copeptin levels in acute hemorrhagic stroke patients are also associated with mortality and poor functional outcome.

\section{Methods}

\section{Study design and setting}

This is a prospective study evaluating copeptin concentrations in consecutive patients with hemorrhagic stroke admitted to the Emergency Department of the University Hospital of Basel, Switzerland from November 2006 until November 2007 [9]. The study was approved by the local ethical committee for human studies (EKBB) and registered in the ISCTRN database (ISCTRN 00390962 and ClincalTrials.gov number NCT00390962). Informed consent was obtained from the patients or their next of kin before enrolment.

\section{Participants}

Forty consecutive patients who were admitted to the emergency department with spontaneous ICH within 72 hours of symptom onset were prospectively analyzed. Patients with a subarachnoid hemorrhage or traumatic ICH were not included.

\section{Neuroimaging}

On the initial CT scan, the ICH volume was assessed with the $A B C / 2$ method[10]. In this method, $A$ is the greatest diameter on the largest hemorrhage slice, $B$ is the diameter perpendicular to $A$, and $C$ is the number of axial slices with hemorrhage multiplied by the slice thickness.

\section{Clinical variables and follow up}

Clinical status and severity of disease were assessed on admission. For clinical assessment, the Glasgow Coma Scale (GCS) was used, and relevant co-morbidities were assessed with the Charlson co-morbidity index $[11,12]$. For the assessment of 30-day mortality and functional outcome at 90 days, structured interviews were carried out by a trained medical student who was blinded to copeptin levels. Functional outcomes were measured with the Barthel Index (BI) [13] and Modified Rankin Scale (mRS) [14]. A favorable outcome was defined as a BI score above 85 and a score below 3 on the mRS. To compare the predictive value of copeptin with combined clinical features, the ICH Score according to Hemphill [15] and the ICH Grading Scale according to Ruiz-Sandoval [16] was used.

\section{Endpoints}

The primary endpoint of this study was the predictive value of copeptin for 30-day mortality in patients with hemorrhagic stroke. 30-day mortality is a common endpoint in prognostic ICH studies[2]. The secondary endpoint was the functional outcome at 90 days, as measured by the $\mathrm{BI}$ and the $\mathrm{mRS}$.

\section{Assays}

Results of the routine blood analyses including sodium concentrations, blood glucose, white blood cells, C-reactive protein $(\mathrm{CRP})(\mathrm{mg} / \mathrm{ml})$ and serum osmolarity were consecutively recorded in all patients. Immediately on admission plasma was collected in plastic tubes containing ethylenediaminetatraacetic acid (EDTA). They were placed on ice and then centrifuged at $3000 \mathrm{~g}$ and plasma was frozen at $-70^{\circ} \mathrm{C}$ until batch-analysis. Copeptin levels were measured with a chemiluminescens sandwich immunoassay with a lower detection limit of the assay of $0.4 \mathrm{pmol} / \mathrm{l}[17]$. In healthy volunteers and under rest, normal copeptin levels have 4.0-4.4 pmol/l as range with only $5 \%$ of values lying outside this range [6].

\section{Statistical analysis}

A logarithmic transformation was performed to obtain a normal distribution for skewed variables (i.e. copeptin concentrations). Discrete variables were expressed as counts (percentage) and continuous variables as medians and interquartile ranges (IQR) unless stated otherwise. Frequency comparisons were performed with the chisquare test. Two-group comparisons were performed with the Mann-Whitney-U test if only two groups were compared and the Kruskal-Wallis one-way analysis of variance was used if more than two groups were being compared. Univariate regression models were calculated to compare the prognostic accuracy of copeptin levels with that of other prognostic parameters. Because of the small number of outcomes, it was not reasonable to perform a multivariate analysis. Receiver-operating-characteristics (ROC) were calculated with the area under the curve (AUC) as an overall prognostic measure. All nonlinear data were $\log$ transformed before being entered into the logistic regression models. To estimate the potential clinical relevance of copeptin for the prediction of mortality, we calculated Kaplan-Meier survival curves and stratified patients on the basis of the median copeptin level, then used the log-rank test to compare the two groups. Correlation analyses were performed with Spearman rank correlation. All testing was two-tailed, and $\mathrm{P}$ values less than 0.05 were considered to indicate statistical significance. All calculations were performed with STATA 9.2 (Stata Corp, College Station, Texas). 


\section{Results}

Baseline Data

The median age of the 40 patients ( $45 \%$ female) was 71 years (IQR 64-78 years), the median GCS on admission was 14 (IQR 13-15). The distribution of the hemorrhage sites were as follows: lobar (47.5\%), basal ganglia (45\%) and infratentorial (7.5\%). The median hematoma volume was $17.8 \mathrm{ml}$ (IQR 6.3-36.3). Median copeptin values of our cohort were 16.3 (IQR 6.3-54.3) pmol/l. The time from symptom onset to blood withdrawal for copeptin determination ranged from 2 to 72 hours. For 7 patients, blood withdrawal was done in the first three hours, for 6 patients between 3 and 6 hours, for 7 between 6 and 12 hours, for 9 patients between 12 and 24 hours and for 11 patients between 24 and 72 hours. Copeptin levels were not significantly different between these groups. Copeptin correlated furthermore with $\mathrm{ICH}$ volume $(\mathrm{r}=0.32, \mathrm{p}<$ $0.05)$, with GCS $(\mathrm{r}=-0.35, \mathrm{p}<0.03)$ and blood glucose $(\mathrm{r}$ $=0.53, \mathrm{p}=0.0008)$ on admission.

Four patients underwent hematoma evacuation, 3 patients received a ventricular drainage. In most cases, ICH was presumed to be due to uncontrolled hypertension. 9 patients $(22.5 \%)$ had been taking antiplatelets or anticoagulant drugs before the ICH occurred.

\section{Primary Endpoint}

On follow-up at 30 days, 6 patients had died, yielding a 30 -day mortality of $15 \%$. None of the patients had died due to withdrawal of care. Table 1 shows the baseline characteristics of the survivors and non-survivors on admission. The non-survivors tended to be older, and were more frequently female. Neurological examination on admission revealed a lower GCS level in non-survivors than in survivors (10 pmol/l (IQR 5-13) vs. $14 \mathrm{pmol} / \mathrm{l}$ (IQR 14-15), $\mathrm{p}=0.009)$. Copeptin levels were significantly higher in non-survivors than in survivors (179.0 $\mathrm{pmol} / \mathrm{l}$ (IQR 33.7- 566.0) vs. $12.9 \mathrm{pmol} / \mathrm{l}$ (IQR 5.2-42.8), p $=0.003$ ) (Figure 1). In univariate logistic regression analysis, only GCS, the volume of the $\mathrm{ICH}$, and the copeptin level were significant predictors of mortality (Table 2). The overall prognostic accuracy of copeptin as assessed in ROC curve analysis (AUC 0.88 (95\%CI 0.75-1.00) was comparable to that of the GCS (AUC 0.82 (95\%CI 0.59$1.00), \mathrm{p}=0.56)$, of the ICH Score[15] (AUC 0.89, (95\%CI 0.76-1.00), $\mathrm{p}=0.94$ ) and the ICH Grading Scale[16] (AUC 0.86 (95\%CI 0.69-1.00), $\mathrm{p}=0.81$ ).

To illustrate the prognostic value of copeptin in predicting mortality, we calculated Kaplan-Meier survival curves and divided the patients into two groups depending on whether their copeptin level was above or below the median value $(16.3 \mathrm{pmol} / \mathrm{l})$. As shown in Figure 2, patients with copeptin levels above the median were significantly more likely to die within 30 days $(\mathrm{p}<0.01)$. These patients had also on admission a significantly lower GCS (13.5 vs $15, \mathrm{p}=0.02)$, higher plasma glucose (7.6 vs $5.9 \mathrm{mmol} / \mathrm{l}, \mathrm{p}=0.03$ ) and higher white blood count (WBC, 9.1 vs $8.5 \times 10^{9} / \mathrm{l}, \mathrm{p}=0.01$ ). All other baseline parameters were not significantly different.

\section{Functional outcome}

On day 90, 18 patients (45\%) had a favorable outcome, which was defined as Barthel score of 85 or more and a Modified Rankin score below 3, while 22 patients (55\%) had an unfavorable outcome. Copeptin levels on admission were significantly higher in patients with an unfavorable outcome (32.4 (IQR 9.5-97.8) vs. 11.9 (IQR 3.2-19.8), $\mathrm{p}=0.04)$. Age, GCS, the volume of $\mathrm{ICH}$, and copeptin levels were significant predictors of functional outcome in univariate logistic regression analysis (Table 3). In ROC analysis, copeptin had an AUC of 0.68 (95\%CI $0.52-$ $0.86)$ which did not differ to any statistically significant extent from the AUC of lesion size (AUC 0.75 (95\%CI $0.60-0.91$ ), $\mathrm{p}=0.28$ ) or of GCS (AUC 0.81 (95\%CI 0.680.94), p = 0.24), the ICH Score [15] (AUC 0.83, (95\%CI 0.71-0.95), $\mathrm{p}=0.14$ ) and the ICH Grading Scale[16] (AUC 0.81 (95\%CI 0.68-0.93), $\mathrm{p}=0.21$ ).

\section{Discussion}

In this prospective study, we demonstrate for the first time that serum copeptin levels measured on admission are associated with 30-day mortality and 90-day functional outcome after $\mathrm{ICH}$.

Copeptin is co-synthesized with vasopressin in the hypothalamus and is released into the portal circulation of the neurohypophysis. Vasopressin contributes to the regulation of osmotic and cardiovascular homeostasis $[18,19]$. In addition, vasopressin activates the hypothalamo-pituitary-adrenal axis through potentiation of corticotropin-releasing-hormone-induced ACTH secretion and thus reflects the individual stress response at a hypothalamic level[20-22]. Copeptin is known to have prognostic value in a variety of diseases, as it reflects disease severity and thus the chance of recovery. For example, copeptin levels are independent predictors of survival in critically ill patients suffering from hemorrhagic and septic shock [23]. Furthermore, copeptin levels have prognostic implications in patients with acute myocardial infarction and in patients with acute heart failure[24,25]. Therefore, it has been hypothesized that the close and reproducible relation of copeptin levels to the degree of activation of the stress axis is the basis of its unique usefulness as a prognostic biomarker [9]. In our study, copeptin was correlated with hematoma volume, which in turn is associated with clinical severity and outcome. In accordance with this hypothesis, an earlier study showed a correlation between the severity of head injury and copeptin levels on admission $[8,26]$. In another study, copeptin was associated with lesion size and clinical 
Table 1: Baseline characteristics of ICH Cohort $(n=40)$

\begin{tabular}{|c|c|c|c|}
\hline & $\begin{array}{c}\text { Survivors } \\
(n=34)\end{array}$ & $\begin{array}{l}\text { Non-Survivors } \\
(n=6)\end{array}$ & $p$ \\
\hline \multicolumn{4}{|l|}{ Demographics } \\
\hline Age (years) & $69.5(61.5-75.8)$ & $80(73.3-82.3)$ & 0.06 \\
\hline Gender (Female) & $38 \%(13)$ & $80 \%(5)$ & 0.04 \\
\hline \multicolumn{4}{|l|}{ Clinical parameters } \\
\hline $\mathrm{GCS}^{*}$ & $15(14-15)$ & $10(4-13)$ & 0.009 \\
\hline Charlson Index & $1(0-1)$ & $1.5(1-2)$ & 0.18 \\
\hline Body Temperature $\left(\mathrm{C}^{\circ}\right)$ & $37.1(36.7-37.4)$ & $36.0(35.9-37.5)$ & 0.32 \\
\hline Hematoma Volume in $\mathrm{ml}$ & $13(5-30)$ & $69(60-75)$ & 0.003 \\
\hline Hypertension & $67.7 \%(23)$ & $100 \%(6)$ & 0.444 \\
\hline Drugs (antiplatelets, anticoagulants) & $26.5 \%(9)$ & 0 & $N A$ \\
\hline ICH Score & $1(0-1)$ & $3(2.5-4)$ & 0.002 \\
\hline ICH Grading Scale & $7(7-8)$ & $9.5(9-11)$ & 0.004 \\
\hline \multicolumn{4}{|l|}{ Location } \\
\hline Basal ganglia & $44.1 \%(15)$ & $50 \%(3)$ & 0.75 \\
\hline Lobar & $47.1 \%(16)$ & $50 \%(3)$ & 0.72 \\
\hline Infratentorial & $8.8 \%(3)$ & 0 & $N A \S$ \\
\hline Presence of IVH $\dagger$ & $20.6 \%(7)$ & $33.3 \%(2)$ & 0.602 \\
\hline \multicolumn{4}{|l|}{ Operation } \\
\hline Surgical hematoma evacuation & $8.8 \%(3)$ & $16.7 \%(1)$ & 0.656 \\
\hline EVD‡ Placement & $8.8 \%(3)$ & 0 & $N A$ \\
\hline \multicolumn{4}{|l|}{ Laboratory Values } \\
\hline Sodium (mmol/l) & $138(136-141)$ & $139(132-141)$ & 0.89 \\
\hline Osmolarity (mosml/l) & $297(293-301)$ & $292(283-300)$ & 0.53 \\
\hline Glucose $(\mathrm{mmol} / \mathrm{l})$ & $6.6(5.8-7.8)$ & $7.7(6.1-8.4)$ & 0.64 \\
\hline White blood count $\left(\times 10^{9} / \mathrm{l}\right)$ & $9.5(6.7-11.6)$ & $8.7(7.5-8.8)$ & 0.58 \\
\hline C-reactive Protein (mg/l) & $6(3-18)$ & $12(3-81)$ & 0.54 \\
\hline Copeptin level (nmol/l) & $12.9(5.2-42.8)$ & $179.0(33.7-566.0)$ & 0.003 \\
\hline
\end{tabular}

Values are presented as median (lower quartile, upper quartile) or \% (counts)

* GCS = Glasgow Coma Scale; † IVH = intraventricular hemorrhage, ₹ EVD = external ventricular drainage; § NA = not available; ICH Score according to Hemphill [15]; ICH Grading Scale according to Ruiz-Sandoval [16]

severity on admission but was still an independent prognostic marker in patients with an acute ischemic stroke [9]. This suggests that copeptin on one hand is associated with the severity of the disease, in ICH patients mirrored by the lesion or the GCS, on the other hand it might still provide additional information related to brain damage.
Copeptin mirrors circulating vasopressin levels and vasopressin itself may also directly influence the clinical course. Data from experimental studies imply that vasopressin plays a role in brain edema formation as blocking of vasopressin receptors attenuates brain edema in ischemic and traumatic mice models[27-29]. The relationship between vasopressin levels and brain edema development 


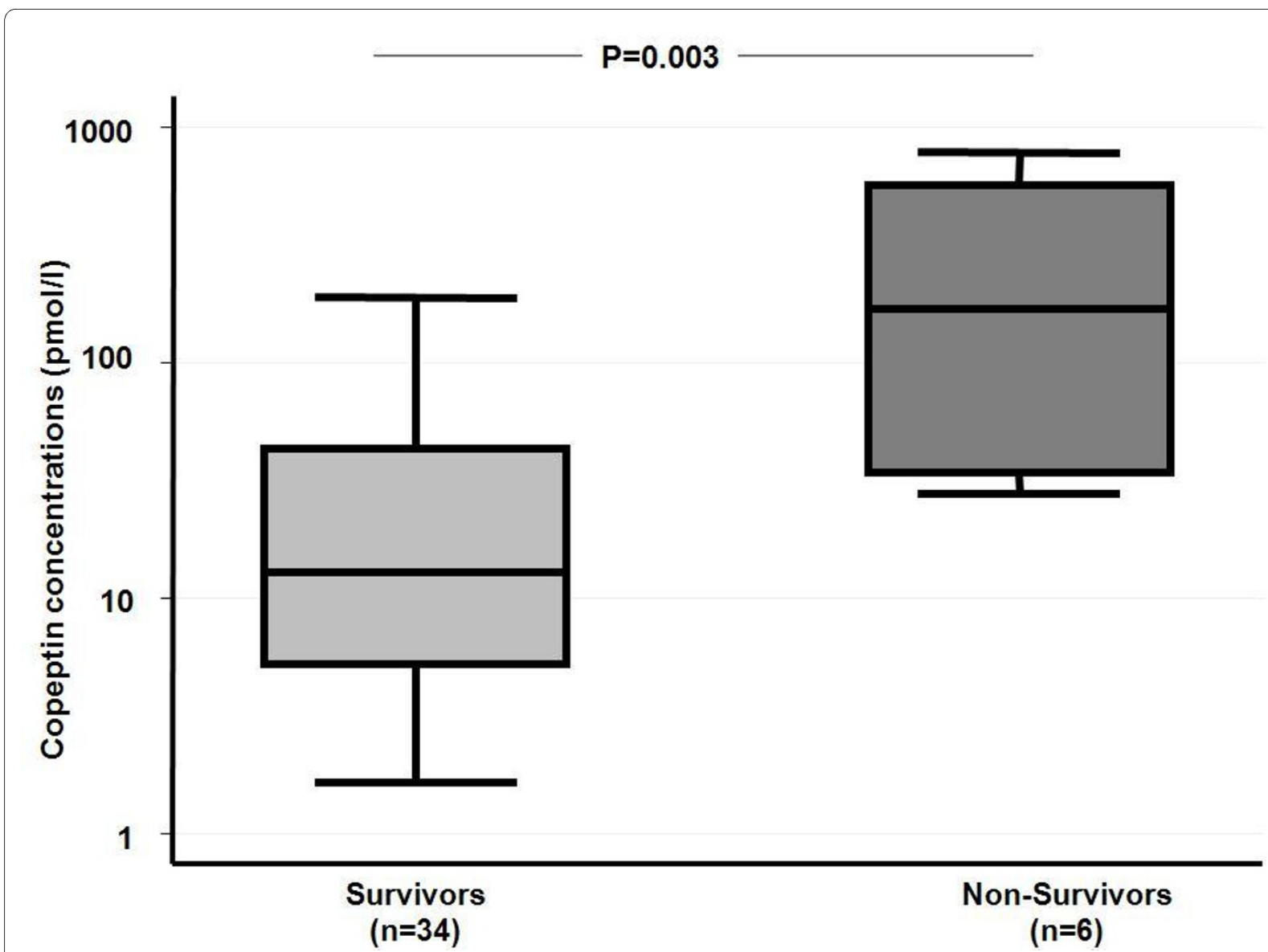

Figure 1 Baseline log copeptin levels in patients who died or survived after ICH. A box encloses the middle 50 percent, where the median is represented as a horizontal line inside the box.

has also been demonstrated in a clinical study of headinjured patients[30]. Brain edema formation predicts an unfavorable outcome in ICH[31]. Therefore, copeptin levels might reflect developing or existing brain edema and might therefore be helpful in identifying patients at risk for brain edema formation who could profit from therapeutic interventions, such as the administration of a vasopressin antagonist[28]. A limitation of our study was that we could not monitor brain edema formation and link it with copeptin values, because imaging studies of the brain were not routinely repeated. Hence, the implication of copeptin and brain edema formation in $\mathrm{ICH}$ remains hypothetical at the moment.

Copeptin predicted mortality and functional outcome in our ICH cohort and its discriminative power was in the range of GCS, hematoma volume and age, which are known to be strong individual outcome predictors, especially when used in combination[15,16,32]. Other biomarkers have been shown to predict early neurologic deterioration and mortality in ICH patients, i.e. D-dimer [33], glutamate [34], matrix metalloproteinases [3] and protein S100b [35]. Each of these biomarkers reflects a different pathophysiological process which also might have a specific therapeutic implication[5]. In our opinion it is advisable to rely the difficult task of prognostic assessment and treatment decisions upon several parameters. In this context copeptin might have an interesting potential as a new prognostic biomarker in combination with clinical features.

Our study cohort was too small to allow a meaningful multivariate analysis. We thus could not determine whether copeptin is an independent prognostic marker that yields additional information beyond that derivable from other known prognostic factors such as GCS and hematoma volume (both of which are correlated with the copeptin level). These associations were expected since GCS and hematoma volume are strong outcome predictors. It has been shown in a larger cohort in patients with ischemic stroke on the other hand that copeptin is a very strong independent prognostic marker (i.e., independent of age, lesion size, glucose, WBC, CRP and clinical severity on admission) for functional outcome and mortality. Thus it is possible that in a larger cohort copeptin might 
Table 2: Prediction of 30 Day mortality $(n=6)$ in univariate analysis of all patients $(n=40)$

\begin{tabular}{lcccc}
\hline Parameter* & Odds Ratio & & $\mathbf{9 5 \%} \mathbf{C l}$ & \multicolumn{1}{c}{} \\
\hline Age & 1.11 & 1.00 & 1.23 & 0.054 \\
Gender & 8.08 & 0.85 & 77.07 & 0.07 \\
GCS & 0.74 & 0.58 & 0.93 & $\mathbf{0 . 0 1}$ \\
Charlson Index & 1.11 & 0.71 & 1.17 & 0.65 \\
Body Temperature & 0.58 & 0.17 & 2.01 & 0.39 \\
Hematoma Volume & 1.05 & 1.08 & $\mathbf{0 . 0 0 6}$ \\
ICH Score & 3.92 & 1.01 & $\mathbf{0 . 0 0 5}$ \\
ICH Grading Scale & 2.94 & 1.49 & 6.42 & $\mathbf{0 . 0 0 7}$ \\
Sodium & 0.94 & 1.34 & 1.29 & 0.709 \\
Osmolarity & 0.87 & 0.69 & 1.10 & 0.256 \\
Glucose & 1.15 & 0.69 & 1.99 & 0.62 \\
CRP & 1.03 & 0.66 & 1.07 & 0.221 \\
WBC & 0.87 & 0.98 & 1.19 & 0.38 \\
Copeptin & 19.48 & 0.63 & 180.64 & $\mathbf{0 . 0 0 9}$ \\
\hline
\end{tabular}

${ }^{*}$ Note that the odds ratio corresponds to a unit increase in the explanatory variable; for copeptin this corresponds to an increase per unit of the log-transformation of copeptin (thus a log transformed increase of 1 corresponds to a copeptin increase of $10 \mathrm{pmol} / \mathrm{I}$ ). ICH Score according to Hemphill [15]; ICH Grading Scale according to Ruiz-Sandoval [16]

prove to be an independent marker also in $\mathrm{ICH}$ patients [9].

Another limitation of our study is that our cohort included both surgically and non-surgically treated patients. Surgical treatment is unlikely to have influenced the prognosis heavily, however, as the STICH trial did not show any significant benefit of early surgery versus initial conservative treatment[36].

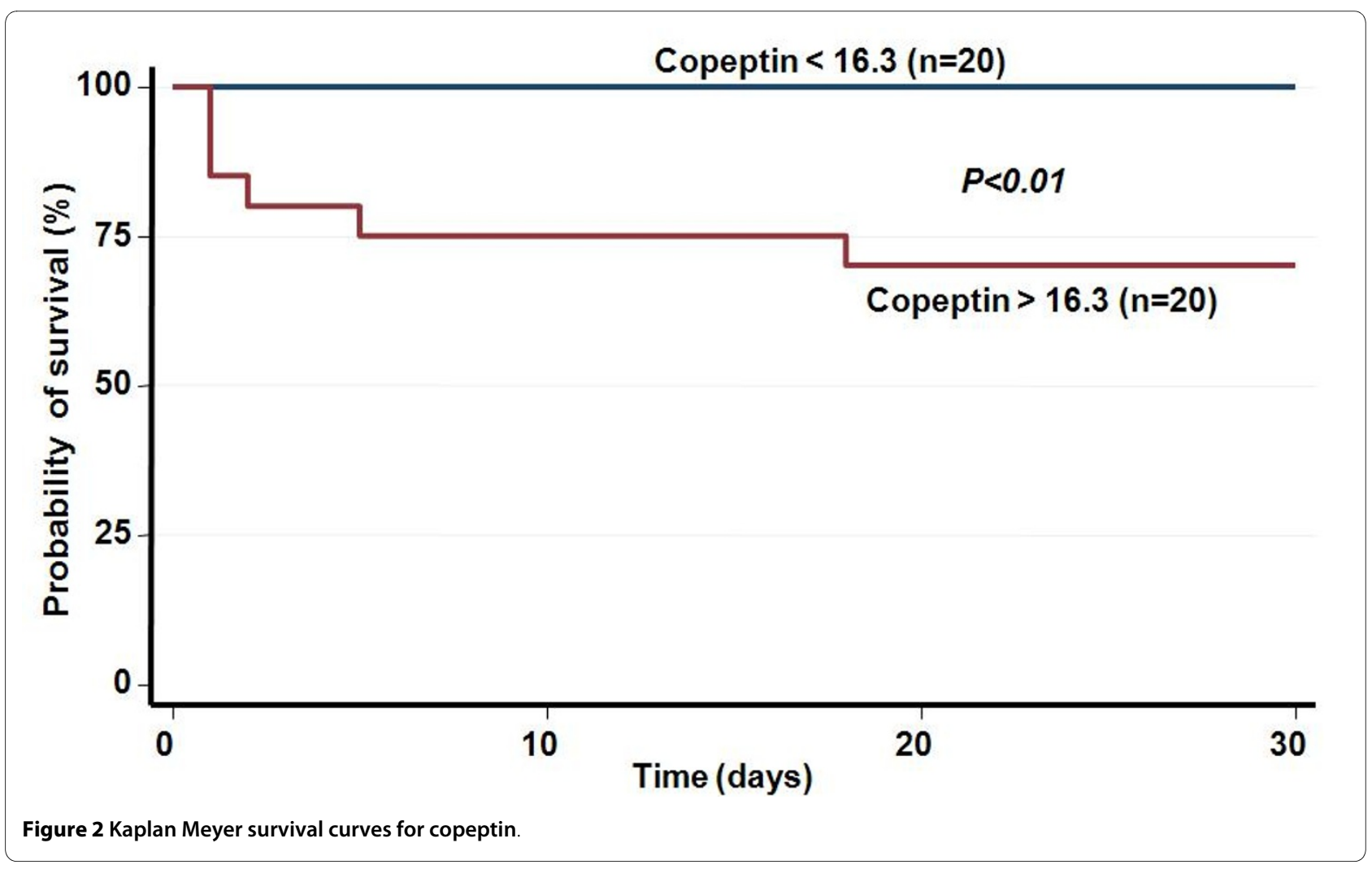


Table 3: Prediction of adverse 90 days outcome defined as a Barthel score $<85$ points and $\mathrm{mRS}<3(\mathrm{n}=22)$ in univariate analysis of all patients $(n=40)$

\begin{tabular}{|c|c|c|c|c|}
\hline Parameter* & Odds Ratio & & & $p$ \\
\hline Age & 1.09 & 1.01 & 1.16 & 0.023 \\
\hline Gender & 2.40 & 0.66 & 8.72 & 0.184 \\
\hline GCS & 0.42 & 0.19 & 0.94 & 0.036 \\
\hline Charlson Index & 1.88 & 0.96 & 3.68 & 0.07 \\
\hline Body Temperature & 0.54 & 0.21 & 1.39 & 0.20 \\
\hline Hematoma Volume & 1.06 & 1.01 & 1.10 & 0.017 \\
\hline $\mathrm{ICH}$ Score & 5.48 & 1.81 & 16.48 & 0.002 \\
\hline ICH Grading Scale & 2.84 & 1.34 & 5.98 & 0.006 \\
\hline Sodium & 1.29 & 0.99 & 1.68 & 0.062 \\
\hline Osmolarity & 1.15 & 0.97 & 1.35 & 0.098 \\
\hline Glucose & 0.99 & 0.66 & 1.51 & 0.98 \\
\hline CRP & 1.04 & 0.98 & 1.10 & 0.188 \\
\hline WBC & 1.03 & 0.86 & 1.24 & 0.73 \\
\hline Copeptin & 3.10 & 1.02 & 9.39 & 0.046 \\
\hline
\end{tabular}

* Note that the odds ratio corresponds to a unit increase in the explanatory variable; for copeptin this corresponds to an increase per unit of the log-transformation of copeptin (thus a log transformed increase of 1 corresponds to a copeptin increase of $10 \mathrm{pmol} / \mathrm{l}$ ). ICH Score according to Hemphill [15]; ICH Grading Scale according to Ruiz-Sandoval [15].

Our study included all patients who presented to the ED within 72 hours after the onset of clinical symptoms, and thus constitutes a heterogeneous population. Due to our limited sample size, we are not able to assess the time effect in our study. In the aforementioned [9] ischemic stroke trial however, a subgroup analysis revealed no difference in the predictive value of the copeptin level depending on whether it was measured 0-3 hours, 3-6 hours, 6-12 hours, 12-24 hours, or 24-72 hours after symptom onset.

\section{Conclusion}

In conclusion, in our cohort of patients with $\mathrm{ICH}$, copeptin was significantly associated with 30 -day mortality and with a poor functional outcome at 90 days. If this finding can be validated and confirmed in larger studies, the measurement of copeptin levels may allow together with other clinical parameters improved risk stratification for $\mathrm{ICH}$ patients in the future.

\section{Abbreviations}

ICH: Intracerebral Hemorrhage; GCS: Glasgow Coma Scale; AUC: Area Unde the Curve; AVP: Arginin-Vasopressin; CRP: C-Reactive Protein; mRS: modified Rankin Scale; BI: Barthel Index.

\section{Competing interests}

NGM is employed by B.R.A.H.M.S., the manufacturer of the copeptinassay (B.R.A.H.M.S. CT-proAVP LIA, B.R.A.H.M.S AG, Hennigsdorf/Berlin, Germany). BM, MCC and PS have served as consultants for B.R.A.H.M.S., from which they have received lecture honoraria, reimbursement of meeting participation fees, and support for research unrelated to the present study. No funding was obtained from commercial sources for this study.

\section{Authors' contributions}

CZ and MK included patients in the study. NGM analyzed the blood samples. PS performed the statistical analysis. MS and AM supported us in collecting the data. BM and MCC participated in the design of the study. All authors read and approved the manuscript.

\section{Acknowledgements}

We are grateful to the nurses, ward physicians, and patients who participated in the study, the Departments of Neurosurgery, Neurology, and Anesthesia, the emergency unit. We thank the staff of the central laboratory of the University Hospital Basel, particularly Melanie Wieland and Heike Freidank, for their help and technical support. This study was supported by in-house grants from the Departments of Endocrinology and Neurology of the University Hospital of Basel, Switzerland as well as by a research grant for young scientist from the University of Basel (to MK) and further by research grants from the Swiss National Foundation (PP00P3-123346, to MCC). We thank Dr. Ethan Taub for proof-reading our manuscript.

\section{Author Details}

1 Department of Neurosurgery, University Hospital of Basel, Spitalstrasse 21, 4031 Basel, Switzerland, 2Department of Neurology, University Hospital of Basel, Petersgraben 4, 4031 Basel, Switzerland, 3Department of Endocrinology and Clinical Nutrition, University Hospital of Basel, Petersgraben 4, 4031 Basel, Switzerland, ${ }^{2}$ Department of Anesthesia, Operative Intensive Care Unit, University Hospital Basel, Spitalstrasse 21, 4031 Basel, Switzerland, 5Department of Research, BRAHMS Aktiengesellschaft, Biotechnology Centre, Neuendorfstrasse 25,16761 Hennigsdorf, Germany and ${ }^{6}$ Department of Internal Medicine, Haus 7, Tellstrasse, 5001 Aarau, Switzerland

Received: 22 February 2010 Accepted: 26 May 2010

Published: 26 May 2010

References

1. Andersen KK, Olsen TS, Dehlendorff C, Kammersgaard LP: Hemorrhagic and ischemic strokes compared: stroke severity, mortality, and risk factors. Stroke; a journal of cerebral circulation 2009, 40(6):2068-2072.

2. Ariesen MJ, Algra A, Worp HB van der, Rinkel GJ: Applicability and relevance of models that predict short term outcome after 
intracerebral haemorrhage. Journal of neurology, neurosurgery, and psychiatry 2005, 76(6):839-844.

3. Alvarez-Sabin J, Delgado P, Abilleira S, Molina CA, Arenillas J, Ribo M, Santamarina E, Quintana M, Monasterio J, Montaner J: Temporal profile of matrix metalloproteinases and their inhibitors after spontaneous intracerebral hemorrhage: relationship to clinical and radiological outcome. Stroke; a journal of cerebral circulation 2004, 35(6):1316-1322.

4. Sacco RL: Predicting stroke outcome: what does the 'stroke prognostocrit level' indicate? Nature clinical practice 2006, 2(11):577.

5. Delgado P, Alvarez Sabin J, Montaner J: [Biological markers in spontaneous intracerebral hemorrhage]. Neurologia (Barcelona, Spain) 2007, 22(7):448-455

6. Morgenthaler NG, Struck J, Alonso C, Bergmann A: Assay for the measurement of copeptin, a stable peptide derived from the precursor of vasopressin. Clinical chemistry 2006, 52(1):112-119.

7. Morgenthaler NG, Struck J, Jochberger S, Dunser MW: Copeptin: clinical use of a new biomarker. Trends in endocrinology and metabolism: TEM 2008, 19(2):43-49.

8. Kleindienst A, Brabant G, Morgenthaler NG, Dixit KC, Parsch H, Buchfelder M: Following brain trauma, copeptin, a stable peptide derived from the AVP precusor, does not reflect osmoregulation but correlates with injury severity. Acta Neurochir Supp/ 106:221-224.

9. Katan M, Fluri F, Morgenthaler NG, Schuetz P, Zweifel C, Bingisser R, Muller K, Meckel S, Gass A, Kappos L, et al.: Copeptin: a novel, independent prognostic marker in patients with ischemic stroke. Annals of neurology 2009, 66(6):799-808.

10. Kothari RU, Brott T, Broderick JP, Barsan WG, Sauerbeck LR, Zuccarello M, Khoury J: The ABCs of measuring intracerebral hemorrhage volumes. Stroke; a journal of cerebral circulation 1996, 27(8):1304-1305.

11. Goldstein LB, Samsa GP, Matchar DB, Horner RD: Charlson Index comorbidity adjustment for ischemic stroke outcome studies. Stroke; $a$ journal of cerebral circulation 2004, 35(8):1941-1945.

12. Gill MR, Reiley DG, Green SM: Interrater reliability of Glasgow Coma Scale scores in the emergency department. Annals of emergency medicine 2004, 43(2):215-223.

13. Mahoney Fl, Barthel DW: Functional Evaluation: the Barthel Index. Maryland state medical journal 1965, 14:61-65.

14. Rankin J: Cerebral vascular accidents in patients over the age of 60. II. Prognosis. Scottish medical journal 1957, 2(5):200-215.

15. Hemphill JC, Bonovich DC, Besmertis L, Manley GT, Johnston SC: The ICH score: a simple, reliable grading scale for intracerebral hemorrhage. Stroke; a journal of cerebral circulation 2001, 32(4):891-897.

16. Ruiz-Sandoval JL, Chiquete E, Romero-Vargas S, Padilla-Martinez JJ, Gonzalez-Cornejo S: Grading scale for prediction of outcome in primary intracerebral hemorrhages. Stroke; a journal of cerebral circulation 2007, 38(5):1641-1644.

17. Fenske W, Stork S, Blechschmidt A, Maier SG, Morgenthaler NG, Allolio B: Copeptin in the differential diagnosis of hyponatremia. The Journal of clinical endocrinology and metabolism 2009, 94(1):123-129.

18. Robertson GL: Antidiuretic hormone. Normal and disordered function. Endocrinology and metabolism clinics of North America 2001, 30(3):671-694. vii.

19. Singh Ranger $\mathrm{G}$ : The physiology and emerging roles of antidiuretic hormone. International journal of clinical practice 2002, 56(10):777-782.

20. Itoi K, Jiang YQ, Iwasaki $Y$, Watson SJ: Regulatory mechanisms of corticotropin-releasing hormone and vasopressin gene expression in the hypothalamus. Journal of neuroendocrinology 2004, 16(4):348-355.

21. Itoi K, Seasholtz AF, Watson SJ: Cellular and extracellular regulatory mechanisms of hypothalamic corticotropin-releasing hormone neurons. Endocrine journal 1998, 45(1):13-33.

22. Katan M, Morgenthaler N, Widmer I, Puder JJ, Konig C, Muller B, ChristCrain M: Copeptin, a stable peptide derived from the vasopressin precursor, correlates with the individual stress level. Neuro endocrinology letters 2008, 29(3):341-346

23. Morgenthaler NG, Muller B, Struck J, Bergmann A, Redl H, Christ-Crain M: Copeptin, a stable peptide of the arginine vasopressin precursor, is elevated in hemorrhagic and septic shock. Shock (Augusta, Ga) 2007 28(2):219-226.

24. Khan SQ, Dhillon OS, O'Brien RJ, Struck J, Quinn PA, Morgenthaler NG, Squire IB, Davies JE, Bergmann A, Ng LL: C-terminal provasopressin (copeptin) as a novel and prognostic marker in acute myocardial infarction: Leicester Acute Myocardial Infarction Peptide (LAMP) study. Circulation 2007, 115(16):2103-2110

25. Stoiser B, Mortl D, Hulsmann M, Berger R, Struck J, Morgenthaler NG, Bergmann A, Pacher R: Copeptin, a fragment of the vasopressin precursor, as a novel predictor of outcome in heart failure. European journal of clinical investigation 2006, 36(11):771-778.

26. Klose M, Juul A, Struck J, Morgenthaler NG, Kosteljanetz M, FeldtRasmussen U: Acute and long-term pituitary insufficiency in traumatic brain injury: a prospective single-centre study. Clinical endocrinology 2007, 67(4):598-606

27. Vakili A, Kataoka H, Plesnila N: Role of arginine vasopressin V1 and V2 receptors for brain damage after transient focal cerebral ischemia. $J$ Cereb Blood Flow Metab 2005, 25(8):1012-1019.

28. Molnar AH, Varga C, Berko A, Rojik I, Parducz A, Laszlo F, Laszlo FA: Inhibitory effect of vasopressin receptor antagonist OPC-31260 on experimental brain oedema induced by global cerebral ischaemia. Acta neurochirurgica 2008, 150(3):265-271.

29. Trabold R, Krieg S, Scholler K, Plesnila N: Role of vasopressin V(1a) and V2 receptors for the development of secondary brain damage after traumatic brain injury in mice. Journal of neurotrauma 2008, 25(12):1459-1465.

30. Xu M, Su W, Huang WD, Lu YQ, Xu QP, Chen ZJ: Effect of AVP on brain edema following traumatic brain injury. Chinesejournal of traumatology = Zhonghua chuang shang za zhi/Chinese Medical Association 2007, 10(2):90-93.

31. Gebel JM Jr, Jauch EC, Brott TG, Khoury J, Sauerbeck L, Salisbury S, Spilker J, Tomsick TA, Duldner J, Broderick JP: Relative edema volume is a predictor of outcome in patients with hyperacute spontaneous intracerebral hemorrhage. Stroke; a journal of cerebral circulation 2002, 33(11):2636-2641

32. Broderick JP, Brott TG, Duldner JE, Tomsick T, Huster G: Volume of intracerebral hemorrhage. A powerful and easy-to-use predictor of 30day mortality. Stroke; a journal of cerebral circulation 1993, 24(7):987-993.

33. Delgado P, Alvarez-Sabin J, Abilleira S, Santamarina E, Purroy F, Arenillas JF, Molina CA, Fernandez-Cadenas I, Rosell A, Montaner J: Plasma d-dimer predicts poor outcome after acute intracerebral hemorrhage. Neurology 2006, 67(1):94-98.

34. Castillo J, Davalos A, Alvarez-Sabin J, Pumar JM, Leira R, Silva Y, Montaner J, Kase CS: Molecular signatures of brain injury after intracerebral hemorrhage. Neurology 2002, 58(4):624-629.

35. Delgado P, Alvarez Sabin J, Santamarina E, Molina CA, Quintana M, Rosell A, Montaner J: Plasma S100B level after acute spontaneous intracerebral hemorrhage. Stroke; a journal of cerebral circulation 2006, 37(11):2837-2839.

36. Mendelow AD, Gregson BA, Fernandes HM, Murray GD, Teasdale GM, Hope DT, Karimi A, Shaw MD, Barer DH: Early surgery versus initial conservative treatment in patients with spontaneous supratentorial intracerebral haematomas in the International Surgical Trial in Intracerebral Haemorrhage (STICH): a randomised trial. Lancet 2005, 365(9457):387-397.

\section{Pre-publication history}

The pre-publication history for this paper can be accessed here: http://www.biomedcentral.com/1471-2377/10/34/prepub

\section{doi: $10.1186 / 1471-2377-10-34$}

Cite this article as: Zweifel et al., Copeptin is associated with mortality and outcome in patients with acute intracerebral hemorrhage BMC Neurology 2010, 10:34 